\title{
Нелинейное сложение оптических импульсов с помощью скрученных многосердцевинных световодов
}

\author{
И.С. Чеховской", О.В. Штырина, М.П. Федорук \\ Новосибирский государственный университет, г. Новосибирск \\ Федеральный исследовательский центр информаџионных и вычислительных технологий, \\ 2. Новосибирск \\ *E-mail: i.s.chekhovskoy@nsu.ru
}

DOI: 10.31868/RFL2020.197-198

Многосердцевинные световоды (multi-core fiber - MCF) к настоящему времени используются в различных областях нелинейной оптики. Несмотря на то, что основным приложением данных волокон является передача данных в телекоммуникационных линиях, МCF также начали активно применяться в лазерных приложениях. В частности, многообещающим направлением является использование MCF для разработки новых мощных источников лазерного излучения. В предыдущих работах $[1,2]$ нами было продемонстрировано, что распространение оптических импульсов в нелинейном режиме может привести к концентрации энергии этих импульсов в пределах определенной сердцевины, обеспечивая при этом сложение, усиление и сжатие введенных в световод импульсов.

В данной работе рассматривается новый подход к сложению и сжатию оптических импульсов с применением скрученных относительно центральной оси MCF. Добавление равномерного вращения качественно меняет динамику оптического поля в МСF и открывает возможность для исследования новых типов нелинейных эффектов, таких как, например, нарушение РТ-симметрии.

Распространение оптического поля в скрученном кольцевом световоде с центральной сердцевиной может быть описано в приближении медленно меняющихся огибающих следующей системой связанных нелинейных уравнений Шредингера (НУШ):

$\left\{\begin{array}{l}i \frac{\partial U_{0}}{\partial z}=D_{0} \frac{\partial^{2} U_{0}}{\partial t^{2}}+\gamma_{0}\left|U_{0}\right|^{2} U_{0}+\sum_{n=1}^{N} C_{0} U_{n} \\ i \frac{\partial U_{n}}{\partial z}=D_{n} \frac{\partial^{2} U_{n}}{\partial t^{2}}+\gamma_{n}\left|U_{n}\right|^{2} U_{n}+C \exp (-i \varphi) U_{n+1}+C \exp (i \varphi) U_{n-1}+C_{0} U_{0}, n=1 \ldots N .\end{array}\right.$

Здесь параметр $\varphi$ задает относительное кручение периферийных сердцевин вокруг центральной оси световода. Для упрощения анализа коэффициенты в системе связанных НУШ в дальнейшем могут быть взяты равными единице.

Влияние скручивания на эффективность схемы сложения оптических импульсов было исследовано на примере 7-сердцевинного световода, для которого ранее был определен режим с наилучшим сложением, достигаемым при одновременном введении гауссовых импульсов $U(t)=\sqrt{P} \exp \left(-t^{2} / \tau^{2}\right)$ с пиковой мощностью $P=0.687$ и шириной $\tau=1.775$ во все сердцевины световода. Параметр $\varphi$ в расчетах изменялся в пределах от 0 до $\pi / 2$. В случае отсутствия кручения волокна расстояние, на котором достигается наилучшее сложение импульсов в центральной сердцевине (92.5\%), равняется $z=1.75$ и определяется как первый достаточно большой максимум пиковой мощности импульса в центральной сердцевине. 

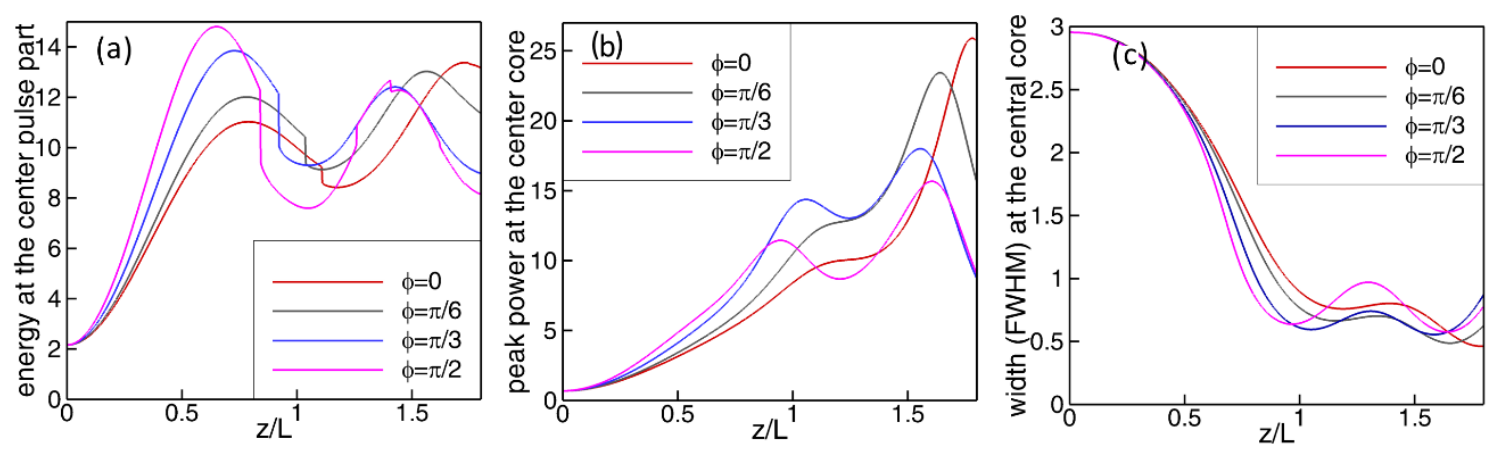

Рис. 1. Изменение характеристик импульса в центральной сердцевине.

На Рис. 1 изображена динамика вдоль МСF различных параметров импульса в центральной сердцевине. Энергия импульса без учета энергии, заключенной в пьедестале импульса, представлена на Рис. 1 (а). Как можно заметить, при увеличении кручения наблюдается смещение точки наиболее эффективного сложения на меньшее расстоянии $(z=0.5)$. Кроме того, эффективность сложения увеличивается до $99 \%$.

На Рис. 1 (b) показана эволюция пиковой мощности импульса вдоль волокна, а на Рис. 1 (c) - изменение ширины импульса на полувысоте. Отметим, что пиковая мощность в точке наилучшего сложения импульсов уменьшается с ростом параметра кручения, а ширина при этом меняется незначительно.

Исследование выполнено при поддержке Российского научного фонда (грант № 20-11-20040). Работа Чеховского И.С. была поддержана грантом 14.Y26.31.0017 Министерства образования и науки.

\section{Литература}

[1] A. M. Rubenchik, et al., Opt. Lett. 40, 721-724 (2015)

[2] I. S. Chekhovskoy, et. al., Phys. Rev. A 94, 043848 (2016) 